\title{
Assessment of Knowledge of Health Workers on Haemophilia at the University of Medical Sciences Teaching Hospital, Ondo State, Nigeria
}

\author{
Osho Patrick ${ }^{1,}$,, Ojo Matilda ${ }^{1}$, Odunlade Olufunke ${ }^{2}$, Okunnuga Ndidi $^{3}$, \\ Gbenga-Fabusiwa Funmilayo ${ }^{4}$, Oni Oluwatosin ${ }^{5}$, Oluwole Mathew \\ ${ }^{1}$ Department of Haematology\& Blood Transfusion, Faculty of Basic Clinical Sciences, University of Medical Sciences, Ondo-City, Nigeria \\ ${ }^{2}$ Department of Paediatrics, Faculty of Clinical Sciences, University of Medical Sciences, Ondo-City, Nigeria \\ ${ }^{3}$ Departments of Radiation and Clinical Oncology, University of Medical Sciences, Ondo-City, Nigeria \\ ${ }^{4}$ Department of Chemistry, University of Medical Sciences Teaching Hospital, Ondo, Ondo State, Nigeria \\ ${ }^{5}$ Department of Haematology/Virology, University of Medical Sciences Teaching Hospital, Akure, Nigeria
}

\section{Email address:}

droshopo@gmail.com (Osho P.), matildaojo4@gmail.com(Ojo M.), drolufunky@gmail.com (Odunlade O.), aishaokunnu@gmail.com (Okunnuga N.), fjgbenga@unimed.edu.ng (Gbenga-Fabusiwa F.), godsprince805@gmail.com (Oni O.), wole4christ@yahoo.com (Oluwole M.)

${ }^{*}$ Corresponding author

\section{To cite this article:}

Osho Patrick, Ojo Matilda, Odunlade Olufunke, Okunnuga Ndidi, Gbenga-Fabusiwa Funmilayo, Oni Oluwatosin, Oluwole Mathew. Assessment of Knowledge of Health Workers on Haemophilia at the University of Medical Sciences Teaching Hospital, Ondo State, Nigeria. American Journal of Laboratory Medicine. Vol. 5, No. 4, 2020, pp. 88-94. doi: 10.11648/j.ajlm.20200504.12

Received: May 24, 2020; Accepted: June 12, 2020; Published: August 5, 2020

\begin{abstract}
Haemophilia is a rare hereditary bleeding disorder that occurs primarily among males. Adequate knowledge of its clinical presentation and management of this disorder by health workers will improve the clinical course of patients having this disorder. The study was done to assess the knowledge of clinical presentation and management of Haemophillia among health workers at the University of Medical Sciences Teaching Hospital Complex, (UNIMEDTHC) Ondo State, Nigeria. A cross sectional hospital based survey was done using questionnaires that were self-administered by the recruited respondents. Completed questionnaires were collated and analyzed with statistical package for Social Sciences Software (SPSS) version 25. A total of 194 health workers participated in the study with a response rate of $89.4 \%$. The respondents comprised of 72 (37.1\%) males and $122(62.9 \%)$ females. Knowledge of the pathogenesis of Haemophilia among the respondents was good 178 (91.8\%). Male predominance of the disorder was ascertained by $148(76.3 \%)$ respondents. About half, $105(54.1 \%)$ of respondents were aware that pain is a symptom among haemophiliacs. One hundred and seventy seven (91.2\%) of the respondents knew that prolonged post circumcision bleeding is a symptom while $160(82.5 \%)$ were aware that joints and muscles are mainly affected by bleeding in Haemophilia. One hundred and eighteen (60.8\%) and 145 (74-4\%) of the respondents were aware that HIV and Hepatitis B and C respectively were possible complications of treatment. The role of genetic counseling in prevention of Haemophillia was ascertained in $88-7 \%$ of the respondents. There is a fairly good knowledge of Haemophillia among the surveyed health workers. There is a need for improved knowledge about Haemophilia among health workers through continuing education to ensure prompt diagnosis and appropriate care of people with this disorder.
\end{abstract}

Keywords: Assessment, Knowledge, Health Workers, Haemophilia 


\section{Introduction}

Haemophilia is a hereditary bleeding disorder that occurs primarily among males. It is characterized by bleeding into muscles and joints and causes chronic pain and joint disease [1]. Haemophilia is the most common hereditary coagulation factor deficiency, which is characterized by an impaired ability to stop bleeding when a blood vessel is broken [2]. According to Valizad et al, the underlying molecular defect is a reduced or dysfunctional synthesis of coagulation factor VIII (Haemophilia A) or coagulation factor IX (Haemophilia B), or coagulation factor XI (Haemophilia C) [3]. While haemophilia $\mathrm{A}$ and $\mathrm{B}$ have an X-linked inheritance, hemophilia $\mathrm{C}$ is autosomal recessive. In these disorders, there is abnormality in haemostasis which can lead to spontaneous or post-traumatic prolonged bleeding and it impacts approximately 400,000 people worldwide [4]. Haemophila A is the most common form with an incidence of 1:10,000 male births worldwide [2, 5], and Haemophilia B has an incidence of 1:20,000-30,000 male births worldwide [6]. Haemophilia remains a lifelong non-curative chronic condition and is associated with significant morbidity [7].

People with bleeding disorders can live healthy and effective lives, however, if left untreated bleeding disorders, specifically haemophilia, can lead to disabling pain, acute joint injury and lethal internal bleeding [8]. Although people at all haemophilia severity levels can bleed as a result of an injury, those with severe forms of the disease often experience spontaneous bleeding [1]. In rare cases, bleeding into vital organs can cause death. Bleeding contributes to the progressive deterioration of joints and muscles and this affects patients' well-being and their everyday activities [9]. Other clinical presentations include haemathrosis, haematoma, pseudotumours, haematuria, unusual bleeding after vaccinations, pain, bloody stool, idiopathic epistaxis, and unexplained irritability in infants [6]. Complications associated with haemophilia includes, hematomas of the soft tissues, intracranial hemorrhages, prolonged bleeding, poor wound healing, prolonged oozing following minor injuries, epistaxis, and ecchymosis [2].

Fahimeh et al in an earlier study opined that early treatment of severe hemorrhage episodes is necessary to reduce long-term complications [10]. Severe bleeding episodes commonly affect the knee, elbow and ankle joints. Early treatment with replacement of essential clotting factor at the time of a bleeding episode can prevent severe joint disease [11]. Prophylaxis can be used to stabilize or improve function in a joint that has bled in the past (secondary prophylaxis) or to prevent bleeding (primary prophylaxis). According to the Universal Data Collection Program of the Centers for Disease Control and Prevention (CDC) [12], 44\% of people with severe hemophilia A (clotting factor VIII deficiency, the more prevalent form of hemophilia) and 33\% of people with haemophilia B (clotting factor IX deficiency) are treated with some form of prophylaxis. The first randomized clinical trial of young children with haemophilia
A on prophylaxis showed improved joint function [13]. Until the past decade, treatment of haemophilia involved intravenous infusion of a human blood-derived clotting factor that was effective in stopping most bleeding episodes, but transmitted blood-borne infections, including HIV and hepatitis A, B, and C. According to the CDC's Haemophilia Surveillance System, 7.5\% of youths with haemophilia were infected with HIV, and 53\% contracted hepatitis C from tainted blood products (CDC, unpublished data, 1998) cited by Nazzaro et al [1]. Newer manufacturing processes such as recombinant technology, implemented in the early 1990s, have since increased the safety of blood products [1]. Adequate knowledge of clinical presentation, early diagnosis and prompt management of haemophillia by health workers can help to prevent or minimize complications when it occurs. This study was conducted to assess the knowledge of health workers at the UNIMEDTHC, Nigeria about the clinical presentation, diagnosis and management of haemophillia

\section{Methodology}

The cross-sectional survey was conducted at the University of Medical Sciences Teaching Hospital Complex, Ondo State, Nigeria in November 2019. The respondents were health workers of the University of Medical Sciences Teaching Hospitals Complex, Ondo State, The teaching hospital has annexes in Akure and Ondo the two largest towns in the state. The study was conducted in the two centers. The research employed a well-structured questionnaire in obtaining data from the respondents. The structured questionnaire was in the following parts: Socio demographic information of the respondents; General knowledge of Haemophilia; Signs and symptoms of Haemophilia; and Treatment, Complications and prevention of Haemophilia. The study sample size was determined using the Krejcie and Morgan table of (1970) at 95\% level of confidence. Hence the sample size of the study was two hundred and seventeen (217).

The respondents were selected using simple random sampling technique, targeting mainly doctors and nurses. Questionnaires were self-administered by the respondents. Ethical clearance for the study was obtained from the Research and Ethics Committee of the hospital. Data was analyzed using Statistical Package for Social Science (SPSS) version 25. Results are represented as descriptive statistics in tables using frequencies and percentages.

\section{Results}

Table 1 on demographics shows there were 194 respondents comprising 72 (37.1\%) males and 122 (62.9\%) females. About half of the respondents (49\%) were above 30 years old. Doctors and nurses accounted for $81.4 \%$ of the respondents while the remaining health workers accounted for $18.4 \%$. 
Table 2 showed $178(91.8 \%)$ of the respondents were aware that hemophilia is hereditary while 148 (76.3\%) agreed that males are predominantly affected. One hundred and eighteen $(60.8 \%)$ of the respondent knew that affected females may have heavy menstrual flow. One hundred and twenty $(61.9 \%)$ knew that the chance of a couple having a boy with Haemophilia if the mother is a carrier is 1 in 4 births. Forty nine $(25.3 \%)$ of the respondents had the impression that haemophilia is curable. About $40.7 \%$ and $21.6 \%$ of the respondents had seen and managed a haemophiliac patient respectively. One hundred and seventy nine $(92.3 \%)$ of the respondent knew that prolonged bleeding in haemophilia is due to deficient or dysfunctional coagulation factor.

Table 3 showed one hundred and seventeen (91.2\%) of the respondents knew prolonged post circumcision bleeding as a common clinical presentation of haemophilia. One hundred and five $(54.1 \%)$ of the respondents knew haemophiliacs could present with pain. One hundred and seventy-seven $(91.2 \%)$ and $130(67 \%)$ of the respondent were aware that internal and external bleeding and bleeding into weight bearing joints respectively could occur in haemophiliacs. One hundred and seventy six $(90.7 \%)$ of the respondents were aware that prolonged bleeding may occur following tooth extraction.

Table 4 showed one hundred and eighty three $(94.3 \%)$ of the respondents knew that diagnosis of haemophilia is mainly by deficient coagulation factor assay while 161 (83\%) thought that replacement therapy is the mainstay of treatment. One hundred and sixty one $(83 \%)$ of the respondents agreed that prophylaxis with factor concentrate in haemophilia management is beneficial. One hundred and eighteen (60.8\%) of the respondents knew HIV infection as a complication of treatment of haemophilia while one hundred and forty five (74.7\%) thought hepatitis B and C infections could also complicate treatment. One hundred and sixty eight $(86.6 \%)$ of the respondents agreed that a comprehensive multidisciplinary approach to the management of haemophilia is the ideal. One hundred and seventy two $(88.7 \%)$ and one hundred and fifty four $(79.4 \%)$ of the respondents knew that genetic counseling and prenatal diagnosis were respectively relevant in the prevention of haemophilia. One hundred and sixty six $(85.6 \%)$ of the respondents were aware that life expectancy is close to normal with appropriate care and treatment for haemophillia..

Table 1. Demographic Characteristics of Respondents.

\begin{tabular}{llll}
\hline & & Frequency & Percent (\%) \\
\hline Gender & Male & 72 & 37.1 \\
Age & Female & 122 & 62.9 \\
& Below 20 years & 13 & 6.7 \\
& $20-29$ years & 86 & 44.3 \\
& $30-39$ years & 62 & 32.0 \\
& $40-49$ years & 27 & 13.9 \\
Designation of Health Workers & 50 years & 6 & 3.1 \\
& Doctors & 92 & 47.4 \\
& Nurse & 66 & 34 \\
& Laboratory workers & 25 & 12.9 \\
Nature of Employment & Health attendants & 2 & 1.0 \\
Insurance Coverage & Midwives & 9 & 4.6 \\
& Full & 134 & 69.1 \\
Duration of Employment & Contract & 60 & 30.9 \\
& Yes & 49 & 25.3 \\
& No & 145 & 74.7 \\
& Less than 1 year & 74 & 38.3 \\
& $1-5$ years & 74 & 38.3 \\
\hline
\end{tabular}

Table 2. Respondents 'Knowledge of the Pathogenesis and Clinical Features of Haemophilia.

\begin{tabular}{|c|c|c|c|}
\hline Questions & Measures & Frequency & Percent (\%) \\
\hline \multirow[t]{3}{*}{ Haemophilia is an inherited rare blood disorder? } & Yes & 178 & 91.8 \\
\hline & No & 13 & 6.7 \\
\hline & I Don't Know & 3 & 1.5 \\
\hline \multirow{2}{*}{ Haemophilia is a common blood disorder? } & No & 111 & 57.2 \\
\hline & I Don't Know & 5 & 2.6 \\
\hline \multirow[t]{2}{*}{ Haemophilia is an infectious disease? } & Yes & 19 & 9.8 \\
\hline & I Don't Know & 6 & 3.1 \\
\hline \multirow[t]{3}{*}{ Prolonged bleeding in Haemophilia is due to deficient or dysfunctional coagulation factor? } & Yes & 179 & 92.3 \\
\hline & No & 11 & 5.7 \\
\hline & I Don't Know & 4 & 2.1 \\
\hline \multirow[t]{2}{*}{ Haemophilia predominantly affects the male? } & Yes & 148 & 76.3 \\
\hline & No & 27 & 13.9 \\
\hline
\end{tabular}




\begin{tabular}{|c|c|c|c|}
\hline Questions & Measures & Frequency & Percent (\%) \\
\hline \multirow{3}{*}{ Haemophilia affects females? } & I Don't Know & 19 & 9.8 \\
\hline & Yes & 110 & 56.7 \\
\hline & No & 64 & 33 \\
\hline \multirow{4}{*}{ Haemophilia is curable? } & I Don’t Know & 20 & 10.3 \\
\hline & Yes & 49 & 25.3 \\
\hline & No & 125 & 64.4 \\
\hline & I Don't Know & 20 & 10.3 \\
\hline \multirow[t]{3}{*}{ Affected females may have heavy menstrual flow? } & Yes & 118 & 60.8 \\
\hline & No & 36 & 18.6 \\
\hline & I Don't Know & 40 & 20.6 \\
\hline \multirow[t]{3}{*}{ The chance of a couple having a boy with Haemophilia, if the mother is a carrier is: ( 1 in 4 births)? } & Yes & 120 & 61.9 \\
\hline & No & 33 & 17.0 \\
\hline & I Don't Know & 41 & 21.1 \\
\hline \multirow{2}{*}{ Have you ever seen a Haemophiliac before? } & Yes & 79 & 40.7 \\
\hline & No & 112 & 57.7 \\
\hline \multirow{4}{*}{ Have you managed a Haemophiliac before? } & I Don’t Know & 3 & 1.5 \\
\hline & Yes & 42 & 21.6 \\
\hline & No & 149 & 76.8 \\
\hline & I Don't Know & 3 & 1.5 \\
\hline
\end{tabular}

Table 3. Respondents' Knowledge of Laboratory Diagnosis, Care, Treatment, Complications and Prevention of Haemophilia.

\begin{tabular}{|c|c|c|c|}
\hline Questions & Measures & Frequency & Percent (\%) \\
\hline \multirow[t]{3}{*}{ Acute or Chronic Pain } & Yes & 105 & 54.1 \\
\hline & No & 61 & 31.4 \\
\hline & I Don’t Know & 28 & 14.4 \\
\hline \multirow[t]{3}{*}{ Prolonged Post Circumcision bleeding } & Yes & 177 & 91.2 \\
\hline & No & 6 & 3.1 \\
\hline & I Don't Know & 11 & 5.7 \\
\hline \multirow[t]{3}{*}{ Prolonged Internal and external bleeding } & Yes & 177 & 91.2 \\
\hline & No & 3 & 1.5 \\
\hline & I Don’t Know & 14 & 7.2 \\
\hline \multirow[t]{3}{*}{ Bleeding into joints spaces spontaneously } & Yes & 160 & 82.5 \\
\hline & No & 15 & 7.7 \\
\hline & I Don't Know & 19 & 9.8 \\
\hline \multirow[t]{3}{*}{$\mathrm{Re}$ - bleeds are a common feature } & Yes & 158 & 81.4 \\
\hline & No & 11 & 5.7 \\
\hline & I Don't Know & 25 & 12.9 \\
\hline \multirow[t]{3}{*}{ Bleeding does not affect weight bearing joints } & Yes & 26 & 13.4 \\
\hline & No & 130 & 67.0 \\
\hline & I Don't Know & 38 & 19.6 \\
\hline \multirow[t]{3}{*}{ Prolonged bleeding after tooth extraction } & Yes & 176 & 90.7 \\
\hline & No & 10 & 5.2 \\
\hline & I Don't Know & 8 & 4.1 \\
\hline \multirow[t]{3}{*}{ Knee Joint is mostly frequently affected } & Yes & 107 & 55.2 \\
\hline & No & 36 & 18.6 \\
\hline & I Don’t Know & 51 & 26.3 \\
\hline \multirow[t]{3}{*}{ Bleeding into the brain may occur } & Yes & 122 & 62.9 \\
\hline & No & 29 & 14.9 \\
\hline & I Don't Know & 43 & 22.2 \\
\hline \multirow[t]{3}{*}{ Bleeding maybe spontaneous } & Yes & 179 & 92.3 \\
\hline & No & 5 & 2.6 \\
\hline & I Don't Know & 10 & 5.2 \\
\hline
\end{tabular}

Table 4. Respondents' Knowledge ofTreatment, Complications and Prevention (TCP) of Haemophilia.

\begin{tabular}{|c|c|c|c|}
\hline Questions & Measures & Frequency & Percent (\%) \\
\hline \multirow[t]{3}{*}{ Coagulation factor assay is most important for diagnosis } & Yes & 183 & 94.3 \\
\hline & No & 3 & 1.5 \\
\hline & I Don’t Know & 8 & 4.1 \\
\hline \multirow[t]{3}{*}{ Deficient coagulation factor replacement is the mainstay in management } & Yes & 161 & 83.0 \\
\hline & No & 10 & 5.2 \\
\hline & I Don’t Know & 23 & 11.9 \\
\hline \multirow[t]{3}{*}{ Prophylaxis with factor concentrate is proactive and beneficial } & Yes & 161 & 83.0 \\
\hline & No & 4 & 2.1 \\
\hline & I Don’t Know & 29 & 14.9 \\
\hline Care and treatment is lifelong & Yes & 164 & 84.5 \\
\hline
\end{tabular}




\begin{tabular}{|c|c|c|c|}
\hline Questions & Measures & Frequency & Percent (\%) \\
\hline \multirow{5}{*}{ Life expectancy is close to normal with appropriate care and treatment. } & No & 8 & 4.1 \\
\hline & I Don't Know & 22 & 11.3 \\
\hline & Yes & 166 & 85.6 \\
\hline & No & 8 & 4.1 \\
\hline & I Don't Know & 20 & 10.3 \\
\hline \multirow[t]{3}{*}{ Genetic counselling is relevant in the prevention of Haemophilia } & Yes & 172 & 88.7 \\
\hline & No & 7 & 3.6 \\
\hline & I Don't Know & 15 & 7.7 \\
\hline \multirow[t]{3}{*}{ Female relatives of the Haemophiliac needs genetic testing. } & Yes & 163 & 84.0 \\
\hline & No & 14 & 7.2 \\
\hline & I Don't Know & 17 & 8.8 \\
\hline \multirow[t]{3}{*}{ Pre - natal diagnosis is important in prevention } & Yes & 154 & 79.4 \\
\hline & No & 14 & 7.2 \\
\hline & I Don't Know & 26 & 13.4 \\
\hline \multirow{3}{*}{ HIV infection may complicate treatment } & Yes & 118 & 60.8 \\
\hline & No & 39 & 20.1 \\
\hline & I Don't Know & 37 & 19.1 \\
\hline \multirow[t]{3}{*}{ Hepatitis B and C may complicate treatment } & Yes & 145 & 74.7 \\
\hline & No & 18 & 9.3 \\
\hline & I Don't Know & 31 & 16 \\
\hline \multirow[t]{3}{*}{ A multidisciplinary comprehensive approach of care and treatment is critical } & Yes & 168 & 86.6 \\
\hline & No & 7 & 3.6 \\
\hline & I Don't Know & 19 & 9.8 \\
\hline \multirow[t]{3}{*}{ Plasma clothing factor level assay is most important } & Yes & 157 & 80.9 \\
\hline & No & 13 & 6.7 \\
\hline & I Don't Know & 24 & 12.4 \\
\hline \multirow[t]{3}{*}{ On demand factor replacement is as effective as prophylaxis } & Yes & 122 & 62.9 \\
\hline & No & 26 & 13.4 \\
\hline & I Don't Know & 46 & 23.7 \\
\hline \multirow[t]{3}{*}{ A specialist team for comprehensive care of Haemophilia is an ideal practice } & Yes & 169 & 87.1 \\
\hline & No & 8 & 4.1 \\
\hline & I Don't Know & 17 & 8.8 \\
\hline
\end{tabular}

\section{Discussion}

This survey assessed the knowledge of the pathogenesis, clinical presentation, diagnosis as well as treatment, complication and prevention of haemophilia among health workers in the University Teaching Hospital Complex, Ondo State, Nigeria. We observed that $178(91.8 \%)$ of the respondents were aware that haemophilia is hereditary while $148(76.3 \%)$ agreed that males were predominantly affected by the disorder. An earlier study reported more than $80 \%$ of the respondents as having high medium knowledge levels about the inheritance pattern of haemophilia A [14]. The inheritance of haemophilia is X-linked recessive, with rare exceptions; males are affected while females are carriers of the trait. Majority of respondents 177 (91.2\%) agreed that prolonged post circumcision bleeding is a common clinical presentation of haemophilia in the newborn period. It is documented that prolonged post circumcision bleeding in the neonate may be the first sign of severe haemophilia $\mathrm{A}$ in a male infant [6]. We noted that $177(91.2 \%)$ respondents agreed that prolonged internal and external bleeds occur, while $130(67 \%)$ were aware that weight bearing joints are mainly affected by spontaneous bleeding in this disorder. We found that $105(54.1 \%)$ of the respondents were aware that pain is a symptom in haemophiliac bleed. The bleeding in haemophilia has been documented to be extremely painful in the acute stage and leads to long-term inflammation and deterioration of the involved joint or muscle $[6,15]$. Both Haemophilia A and B are characterized by prolonged and repeated bleeding episodes particularly into muscles and joints [6]. Dental extraction is the most frequent surgical procedure performed in them and the resultant bleeding could be prolonged [16, 17]. In this study $176(90.7 \%)$ of the respondents were aware that prolonged bleeding may occur post tooth extraction. A large number of the respondents in this study knew that the diagnosis of haemophilia is mainly by coagulation factor assay. Diagnosis of haemophilia has been established to be by specific quantitative coagulation factor assay [2]. One of the major challenges of management of haemophilia in most developing countries is with case definition, with resultant missed diagnosis $[18,19]$. It has been reported that complications of haemophilia can be decreased or prevented with improved quality of life through early diagnosis and appropriate treatment [5]. Most of the respondents $161(83.0 \%)$ in this study agreed that replacement of deficient coagulation factor is the mainstay of management of haemophilia. This is similar to the result of a previous study where most of the respondents had good knowledge of treatment of haemophilia [20]. One hundred and sixty-one respondents $(83.0 \%)$ agreed that prophylaxis with coagulation factor concentrate in haemophilia management is both proactive and beneficial. Specific coagulation factor replacement following every bleeding episode, or as prophylaxis given twice or thrice weekly is reported as the therapy of choice in Haemophilia A [21]. In 
most developing nations, there is little or no access to coagulation factor concentrates hence a greater morbidity and mortality among the haemophiliacs in these nations [22]. Recombinant products have been increasingly regarded as the preferred choice for management of haemophilia due to its low risk for viral infection [21].

One hundred and eighteen (60.8\%) and 145 (74-4\%) of the respondents were aware that $\mathrm{HIV}$ and Hepatitis B and C respectively were possible complication of treatment. Considerations for prevention of transfusion transmissible infection is important while deciding on therapeutic choices. The use of virus inactivated concentrates or detergent treated plasma derivates are considered safe when available while the use of untreated concentrates and plasma products is discouraged [23].

We observed that only $79(40.7 \%)$ of respondents had seen a haemophilia patient before while $42(21.6 \%)$ had managed one. This might suggest under diagnosis of the disease and not a true reflection of how prevalent the disorder is. Studies have shown that majority of haemophiliacs living in developing countries were being under diagnosed and undertreated [18, $20]$. One hundred and sixty-eight $(86.6 \%)$ of the respondents in this study opined that a comprehensive multidisciplinary approach to treatment is the ideal. Comprehensive multidisciplinary approach has been judged as the optimal health care option for haemophiliacs [24, 25]. One hundred and seventy two $(88.7 \%)$ and $154(79.4 \%)$ of the respondents were aware that genetic counseling and prenatal diagnosis were relevant in the prevention of haemophilia respectively. Genetic counseling services integrated with antenatal care services will enable women with risks for having a child with haemophilia make an informed choice in relation to family planning. Among the respondents, 166 (85.6\%) were aware that life expectancy may be close to normal with appropriate care and treatment for haemophiliacs. Life expectancy of a child born with haemophilia in Ireland is essentially normal with an excellent quality of life [2]. However this might not be the case in most developing nations where haemophiliacs were being under diagnosed and undertreated

\section{Conclusion}

Knowledge of clinical features and management of haemophilia should be improved among health workers, through continuing education. This would facilitate prompt recognition of cases and referral to experts for appropriate management. The use of multi-disciplinary approach which has been judged as the optimal model of care as well as training and re-trainning of experts will go a long way to stem the incidence of under diagnosis and under treatment of patients with haemophilia.

\section{References}

[1] Nazzaro AM, Owens S, Hoots WK, and Larson KL (2006). Knowledge, attitudes, and behaviors of youths in the US hemophilia population: results of a national survey. $\mathrm{Am} J$ Public Health. 2006; 96 (9): 1618-22.
[2] Balogun TM, Agboola MB, Onigbinde OO, et al (2018). Haemophilia Knowledge among Health Care Providers in a Tertiary Hospital Lagos, Nigeria. Journal of Blood Disorders, Symptoms \& treatments.

[3] Valizadeh L, Hosseini FA, Zamanzadeh V, et al. (2015). Practice of Iranian Adolescents with Hemophilia in Prevention of Complications of Hemophilia. Indian J Palliat Care. 2015; 21 (3): 328-337.

[4] Treatment of Hemophilia: Psychosocial Care for People with Hemophilia. Canada: world federation of hemophilia (WFH); 2007.

[5] Luy J, Wu W, Xiang Z, and Huang F. (2016). Large hemorrhage due to venipuncture in the elbow of a patient with severe hemophilia: A case report and literature review. ExpTher Med. 2016; 11 (3): 1023-1026.

[6] Zaiden RA (2017). Hemophilia B. Practice Essentials. 2017; $1-2$.

[7] Sokal EM, Lombard C, and Mazza G. Mesenchymal. (2015). Stem cell treatment for hemophilia: a review of current knowledge. J ThrombHaemost. 2015; 13 (1): S161-S166.

[8] Karin Knobe and Erik Berntorp. Haemophillia and joint disease: pathophysiology, evaluation and management. J Comorb. 2011; 1: 51-59.

[9] Scalone L, Mantovani LG, Mannucci PM, Gringeri A, and Cocis (2006). Study Investigators. Quality of life is associated to the orthopaedic status in haemophilic patients with inhibitors. Haemophilia. 2006; 12 (2): 154-62.

[10] Fahimeh Alsadat Hoseini, Leila Valizadeh, Vahid Zamanzadeh, Solmaz Fallahi, and Mina Ramezan Behtash (2014). Knowledge, Attitudes and Practices of Preventing Complications among Adolescents with Severe Hemophilia. Thrita. 2014 June; 3 (2): e8758. DOI: 10.5812/thrita.8758.

[11] Rodriguez-Merchan EC. Prevention of the Musculoskeletal Complications of Haemophillia. Advances in Preventive Medicine. 2012. https://doi.org/10.1155/2012/201271.

[12] Report on the Universal Data Collection Program. Atlanta, Ga: Centers for Disease Control and Prevention; 2005.

[13] Manco-Johnson MJ, Abshire TC, Brown D, et al. (2005). Initial results of a randomized, prospective trial of prophylaxis to prevent joint disease in young children with factor VIII (FVIII) deficiency. Paper presented at Annual Meeting of the American Society of Hematology, December 2005, Atlanta, Ga.

[14] Miller KL, Guelcher C, Taylor A. Haemophilia A: patients' knowledge level of treatment and sources of treatment-related information. Haemophilia. 2009; 15 (1): 73-77.

[15] Witkop M, Lambing A. Knowledge and attitudes survey in bleeding disorders providers regarding pain. Haemophilia. 2015; 21 (6): e465-e471.

[16] Drelich DA, Besa CS, Furlonf MA, et al. Hemophilia A. Practice Essentials. 2017; 1-2.

[17] Roberts HR, Escoban M, White GC. Hemophilia A and Hemophilia B. In Lichtman AM, Beutler E, Kipps TJ, Seligsohn U, Kaushan K, Prchal TJ, (eds) Williams Haematology. 7th edition. McGraw-Hill Medical Publishing. 2006; 1867-1874. 
[18] KapilSaxena. Barriers and perceived limitations to early treatment of hemophilia. J Blood Med. 2013; 4: 49-56.

[19] O'Mahony B, Black C. Expanding hemophilia care in developing countries. SeminThrombHemost. 2005; 31: 561568.

[20] Novais T, Duclos A, Varin R, Lopez I, Chamouard V. Treatment-related knowledge and skills of patients with haemophilia and their informal caregivers. Int J Clin Pharm. 2016; 38 (1): 61-69.

[21] Srivastava A, Brewer A. K, Mauser-Bunschotem E. P, Key N. S, Kitchen S, Llinas A et al. Guidelines for the management of haemophilia. Haemophilia. 2013; 19: e1-e47.
[22] Young G. New challenges in hemophilia: long-term outcomes and complications. Hematology Am SocHematolEduc Program. 2012; 362-368.

[23] Palla R, Peyvandi F, Shapiro AD. Rare bleeding disorders: diagnosis and treatment. Blood. 2015; 26: 125 (13): 2052-61.

[24] Coppola A, Morfini M, Cimino E, et al. Blood Transfus. 2014; 12 (Suppl 3): s554-s562.

[25] Ruiz-Saez A. Comprehensive care in hemophilia. Hematology. 2012; 17: 141-144. 